\title{
Pola karakteristik ilustrasi model dalam lembar kerja siswa (LKS) biologi MGMP kelas 11 SMA Negeri di Kota Semarang
}

\author{
Mira Esti Kusumaningrum ${ }^{1 *}$, Fenny Roshayanti ${ }^{2}$, Ipah Budi Minarti ${ }^{3}$ \\ Pendidikan Biologi, FPMIPATI, Universitas PGRI Semarang, Sidodadi, Semarang, 50232 \\ 1 esti.mira13@gmail.com*; fennyrosh@gmail.com; ${ }^{3 i p e h \_m i 2 n @ y a h o o . c o . i d ~}$ \\ *korespondensi penulis
}

\begin{abstract}
Abstrak
Penelitian pola karakteristik ilustrasi model dalam Lembar Kerja Siswa (LKS) MGMP Biologi Kelas 11 SMA Negeri di Kota Semarang ini bertujuan untuk mengetahui pola karakteristik ilustrasi model dalam LKS tersebut. LKS karya MGMP yang digunakan dalam penelitian ini didasarkan pada hasil studi pendahuluan terhadap Tim MGMP Biologi SMA Kota Semarang. Analisis difokuskan terhadap karakteristik ilustrasi model. Data yang diperoleh selanjutnya dianalisis menggunakan analisis kualitatif. Hasil penelitian menunjukkan bahwa karakteristik ilustrasi yang terdiri dari 3 subkategori, subkategori model struktural lebih banyak ditemukan, yaitu sebanyak 67 atau $51,53 \%$ dibandingkan model fungsional yang berjumlah 36 atau 27,69\%, dan model struktural-fungsional yang berjumlah 27 atau 20,76\%. Hasil analisis pola karakteristik ilustrasi model dalam LKS MGMP Biologi Kelas 11 tersebut sesuai dengan ciri-ciri Ilmu Biologi, serta karakteristik jenis pengetahuan yang terdiri dari faktual, konseptual, dan prosedural.
\end{abstract}

Kata kunci: fungsional, ilustrasi, karakteristik, model, struktural, strukturalfungsional

\begin{abstract}
The study of the illustrative characteristic patterns of the models in the MGMP Biology Students 11th Grade Worksheet of State Senior High Schools in Semarang City aims to find out the characteristic patterns of the model illustrations in the worksheet. The MGMP worksheet used in this study was based on the results of a preliminary study of the Semarang MGM Biology Team in the SMA. The analysis is focused on the illustrative characteristics of the model. The data obtained were then analyzed using qualitative analysis. The results showed that the illustrative characteristics consisting of 3 subcategories, structural subcategories were found more, as many as 67 or $51.53 \%$ compared to functional models totaling 36 or $27.69 \%$, and structural-functional models totaling 27 or $20,76 \%$. The results of the analysis of the illustrative characteristic patterns of the Class 11 MGMP Biology Worksheet are in line with the characteristics of Biology, as well as the types of knowledge that consist of factual, conceptual, and procedural.
\end{abstract}

Keywords: functional, illustration, characteristics, model, structural, structural-functional

\section{PENDAHULUAN}

Revolusi industri 4.0 memiliki dampak tersendiri terhadap dunia pendidikan. Tantangan yang akan dihadapi dari perspektif dunia pendidikan tersebut antara lain adanya perubahan 
perilaku generasi $\mathrm{Z}$ dalam konteks pembelajaran, dari segi perubahan kebiasaan belajar siswa dan metode pembelajaran yang diterapkan guru (Wardani, 2018). Dalam pembelajaran sains khususnya biologi, perubahan-perubahan yang akan terjadi tersebut dapat dihadapi secara preventif dengan adanya pemahan khusus dalam salah satu bahan ajar seperti Lembar Kerja Siswa (LKS) berkaitan dengan pemodelannya. LKS menekankan terlebih dahulu suatu fenomena yang bersifat konkrit, sederhana, dan berkaitan dengan konsep yang akan dipelajari. LKS memuat apa yang harus dilakukan siswa, meliputi melakukan, mengamati, dan menganalisis. LKS juga membantu siswa menerapkan dan mengintegrasikan berbagai konsep yang telah ditentukan. LKS juga bermanfaat sebagai penguatan materi yang sebelumnya telah disampaikan oleh guru. Sehingga proses pembelajaran dapat terpusat pada siswa dan sesuai dengan tujuan Kurikulum 2013 (Prastowo dalam Malahayati, 2017).

LKS memiliki pengaruh yang lebih baik daripada penggunaan media buku paket dalam meningkatkan kemampuan berpikir kritis dan hasil belajar siswa. Selain mampu meningkatkan kemampuan berpikir kritis siswa dalam proses pembelajaran, LKS juga dapat berpengaruh terhadap motivasi belajar siswa, seperti LKS berbasis Higher Order Thinking skills (HOTs) pada penelitian Karsono (2017). Hal ini disebabkan karena beberapa faktor, antara lain LKS berbasis HOTs dapat mendorong rasa senang siswa karena menampilkan konsep yang tidak bisa diamati secara langsung dengan media lain.

Hal ini kemudian menjadi sangat penting karena pada penelitian Gogolin dan Kruger (2018) menunjukkan bahwa siswa melihat model sebagai representasi ideal dari wujud yang asli dan memiliki tujuan untuk mendeskripsikannya, sehingga siswa dengan mudah memahami setiap materi yang dipelajarinya. Pemodelan dapat dijadikan sebagai alat generatif untuk menjelaskan suatu fenomena. Hal ini selaras dengan hasil penelitian Schwarz et al. (2009) yang menunjukkan keberhasilan siswa tingkat sekolah dasar dan menengah dalam menggunakan model untuk mengartikulasikan proses atau mekanisme yang mendasari suatu fenomena hingga mampu membuat hipotesis dari fenomena tersebut.

Siswa dalam proses pembelajaran sains sering dianggap memiliki pengetahuan yang sederhana tentang praktik epistemik, namun pada penelitian Pluta et al., (2009) menemukan bahwa siswa memiliki berbagai ide tentang kriteria epistemik untuk model yang baik, antara lain kriteria epistemik primer yang terkait dengan fungsi penjelasan model, peran bukti, detail yang tepat, dan akurasi. Kriteria yang terkait dengan penyusun model menyarankan agar siswa melihat model sebagai lebih dari sekadar salinan langsung atau model skala. Dalam hal ini siswa dianggap memiliki berbagai ide yang dapat dimanfaatkan dalam pemahaman tentang praktik pemodelan. 
Pandangan tentang sifat pemodelan dalam penelitian Seok dan Jin (2011) terangkum dalam lima subtopik, yaitu makna model, tujuan pemodelan, multiplisitas model ilmiah, perubahan dalam model ilmiah dan penggunaan model di kelas sains. Pertama, model dapat didefinisikan sebagai representasi target dan berfungsi sebagai 'jembatan' yang menghubungkan teori dan fenomena. Kedua, model memiliki peran menggambarkan, menjelaskan dan memprediksi fenomena alam dan mengkomunikasikan ide-ide ilmiah kepada orang lain. Ketiga, beberapa model dapat dikembangkan dalam ilmu karena para ilmuwan mungkin memiliki ide yang berbeda tentang seperti apa target itu terlihat dan bagaimana cara kerjanya dan karena itu ada berbagai sumber semiotik yang tersedia untuk membangun model. Keempat, ilmiah model diuji secara empiris dan konseptual dan berubah seiring dengan proses pengembangan pengetahuan ilmiah. Kelima, di ruang kelas sains, tidak hanya guru tetapi juga siswa mengambil keuntungan dari model karena mereka terlibat dalam berbagai kegiatan pemodelan.

Berkaitan dengan aspek karakteristik dari model, Werner et al., (2017) dalam penelitiannya telah mengidentifikasi empat kategori penting, yaitu tingkat abstraksi, tingkat kerumitan, aspek ilustrasi dan penyesuaian untuk pembelajaran. Karakteristik ilustrasi model dapat digolongkan ke dalam tiga jenis subkategori, yaitu model struktural, fungsional model, atau kombinasi keduanya. Dengan demikian, model struktural membantu untuk menggambarkan anatomi dan aspek morfologis dari objek nyata (Belzen dan Kruger, 2010 dan White et al., 2011).

Berdasarkan latar belakang tersebut, maka perlu dilakukan sebuah penelitian tentang pemodelan dalam LKS Biologi sebagaimana LKS menjadi salah satu penunjang keberhasilan dalam proses pembelajaran melalui penelitian yang berjudul, "Pola karakteristik ilustrasi model dalam Lembar Kerja Siswa (LKS) MGMP Biologi kelas 11 SMA Negeri di Kota Semarang". Berdasarkan identifikasi masalah yang telah dipaparkan, maka fokus dan tujuan penelitian ini adalah mengetahui pola karakteristik ilustrasi model dalam Lembar Kerja Siswa (LKS) MGMP Biologi Kelas 11 SMA Negeri di Kota Semarang. Hasil analisis pola karakteristik ilustrasi model dalam LKS ini nantinya diharapkan dapat menjadi bahan acuan sebagai penelitian lainnya, serta mampu menjadi acuan pengajar dalam mengembangkan bahan ajar khususnya LKS menggunakan pemodelan. 


\section{METODE}

Penelitian mengenai "Pola karakteristik ilustrasi model dalam Lembar Kerja Siswa (LKS) MGMP Biologi kelas 11 SMA Negeri di Kota Semarang” ini merupakan penelitian kualitatif. Subjek penelitian ini meliputi LKS Biologi Kelas 11 yang disusun oleh Tim MGMP Biologi Kota Semarang yang berfokus pada karakteristik ilustrasi model dalam LKS tersebut. Instrumen penelitian merupakan suatu alat yang digunakan untuk mengetahui pola tipe model. Instrumen penelitian yang digunakan terdiri atas tabel analisis yang memuat identitas buku, indikator karakteristik ilustrasi model. Teknik pengumpulan data dalam rangka mengetahui pola karakteristik ilustrasi dilakukan melalui wawancara terbuka terlebih dahulu pada Tim MGMP Biologi, serta dokumentasi terhadap data dalam LKS yang berkenaan dengan model tersebut. Metode analisis data kualitatif dilakukan dengan tiga jalur (Huberman, Miles, dan Saldana, 2014), yaitu kondensasi data, penyajian data, dan penarikan kesimpulan. Data hasil penelitian berupa data karakteristik ilustrasi model, kemudian diperiksa keabsahan datanya sesuai untuk penelitian kualitatif yang meliputi validitas internal, validitas eksternal, reliabilitas, objektivitas (Sugiyono, 2018).

\section{HASIL DAN PEMBAHASAN}

Analisis pola karakteristik ilustrasi model dilakukan terhadap seluruh materi yang termuat di LKS Biologi Kelas 11 Semester 1 dan 2 yang terdiri atas 11 BAB, yaitu materi struktur dan fungsi, struktur dan fungsi jaringan pada tumbuhan, struktur dan fungsi jaringan pada hewan, sistem gerak, sistem peredaran darah, sistem pencernaan makanan, sistem respirasi, sistem ekskresi, sistem koordinasi, sistem reproduksi, serta sistem imunitas. Hasil penelitian berupa data hasil analisis pola karakteristik ilustrasi model yang terbagi atas 3 subkategori, yaitu model struktural, model fungsional, dan model struktural-fungsional, serta dilengkapi dengan deskripsinya yang disajikan dalam Tabel 1 mengenai frekuensi karakteristik ilustrasi model, sebagai berikut:

Tabel 1. Frekuensi Karakteristik Ilustrasi Model

\begin{tabular}{ccccccccccccccc}
\hline \multirow{2}{*}{ Kategori } & $\begin{array}{c}\text { Sub } \\
\text { Kategori }\end{array}$ & $\mathbf{1}$ & $\mathbf{2}$ & $\mathbf{3}$ & $\mathbf{4}$ & $\mathbf{5}$ & $\mathbf{6}$ & $\mathbf{7}$ & $\mathbf{8}$ & $\mathbf{9}$ & $\mathbf{1 0}$ & $\mathbf{1 1}$ & Jumlah & $\%$ \\
\hline $\begin{array}{c}\text { Model } \\
\text { Aspek }\end{array}$ & 15 & 9 & 11 & 11 & 1 & 4 & 0 & 3 & 8 & 3 & 2 & 67 & $51,53 \%$ \\
$\begin{array}{c}\text { struktural } \\
\text { Model } \\
\text { Ilustrasi }\end{array}$ & 2 & 0 & 0 & 2 & 4 & 8 & 7 & 4 & 6 & 0 & 3 & 36 & $27,69 \%$ \\
& $\begin{array}{c}\text { fungsional } \\
\text { Model } \\
\begin{array}{c}\text { Mtruktural- } \\
\text { fungsional }\end{array}\end{array}$ & 5 & 4 & 1 & 6 & 1 & 1 & 1 & 0 & 4 & 3 & 1 & 27 & $20,76 \%$ \\
\hline
\end{tabular}


Tabel 1 menunjukkan kategori karakteristik ilustrasi model dalam LKS MGMP Biologi Kelas 11 Semester 1 dan 2. Pada kategori aspek ilustrasi, subkategori model struktural lebih banyak ditemukan dalam LKS, yaitu sebanyak 67 atau 51,53\% dibandingkan model fungsional yang berjumlah 36 atau 27,69\%, dan model struktural-fungsional yang berjumlah 27 atau 20,76\%. Berdasarkan Tabel 1, ringkasan data hasil penelitian mengenai karakteristik ilustrasi model dalam LKS MGMP Biologi Kelas 11 Semester 1 dan 2 dapat dilihat pada Gambar 1

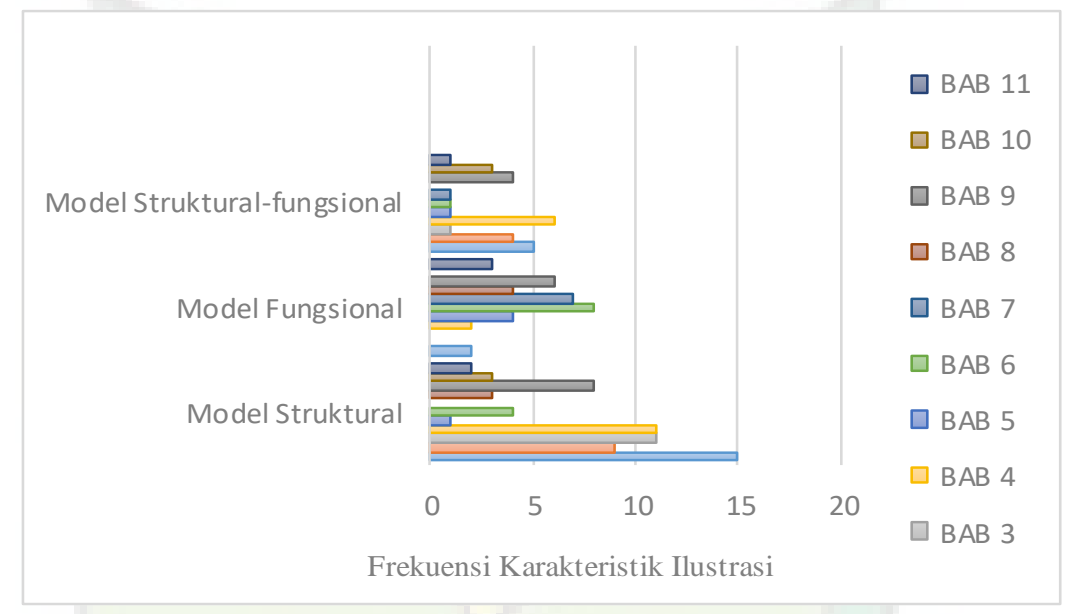

Gambar 1. Frekuensi Karakteristik Ilustrasi Model

Berdasarkan Gambar 1, dapat diketahui bahwa model struktural lebih mendominasi pada BAB 1, yaitu sebanyak 15 dan sama sekali tidak ditemukan di BAB 7. Model fungsional lebih mendominasi pada BAB 6, yaitu sebanyak 8 dan sama sekali tidak ditemukan di BAB 2, 3, dan 10. Model struktural-fungsional lebih mendominasi pada BAB 4, yaitu sebanyak 6 dan tidak ditemukan pada BAB 8.

Subkategori model struktural lebih banyak ditemukan dalam LKS. Hal ini jika dikaitkan dengan jenis-jenis pengetahuan, maka yang terdiri atas pengetahuan faktual, konseptual, prosedural, dan metakognitif, maka benar adanya jika model struktural lebih mendominasi. Pada dasarnya, dalam Ilmu Biologi sepertinya yang telah diulas pada bagian tipe model, memiliki objek-objek yang perlu dimodelkan dalam upaya memudahkan pemahaman siswa. Pada jenis pengetahuan konseptual menekankan keterkaitan antara unsur-unsur dasar dalam struktur yang lebih besar dan semuanya berfungsi bersama-sama. Pengetahuan konseptual mencakup skema, model pemikiran, dan teori baik yang implisit maupun eksplisit. Selain itu, mencakup pula pengetahuan tentang teori, model, dan struktur, serta pengetahuan tentang prinsip dan generalisasi dan saling keterkaitan antara keduanya yang menghasilkan kejelasan terhadap suatu fenomena yang kompleks (Widodo, 2005). 
Karakteristik ilustrasi terdiri atas subkategori model stuktural, model fungsional, dan model stuktural-fungsional. Menurut Belzen dan White et al. dalam White et al. (2017) karakteristik ini mampu membuat perbedaan antara memvisualisasikan aspek dari suatu objek. Dari data analisis pada Tabel 1 dapat diketahui bahwa model struktural lebih mendominasi pada seluruh BAB sebanyak 67 dibanding model yang lain. Adapun contoh materi yang tergolong dalam model struktural, disajikan dalam Gambar 2 sebagai berikut:

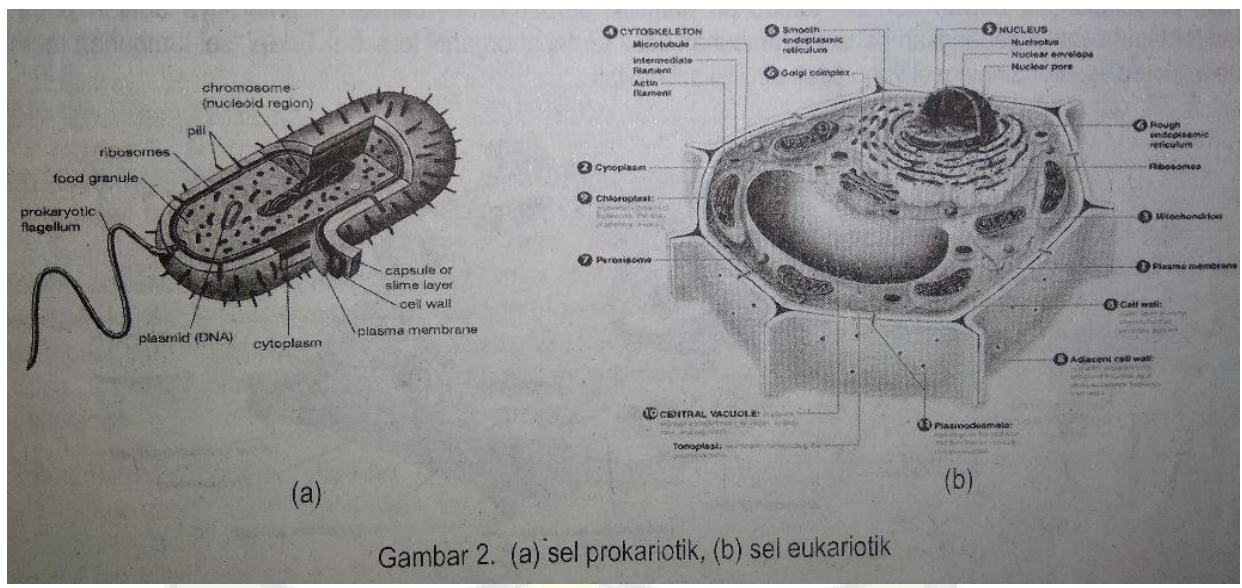

Gambar 2. Contoh Karakteristik Ilustrasi Subkategori Model Struktural 1A/3a

Gambar 2 merupakan contoh dari karakteristik ilustrasi subkategori model struktural pada kode 1A/3a yang berarti sebuah contoh dari materi semester 1, BAB 1, materi struktur dan fungsi, terdapat pada halaman 3 LKS, gambar pertama pada halaman tersebut. Dari Gambar 2 menjelaskan sebuah struktur dari sel prokariotik maupun sel eukariotik. Dari kedua gambar tersebut dapat diketahui dengan jelas struktur-struktur yang ada pada kedua jenis sel tanpa menjelaskan setiap fungsinya secara rinci.

Berdasarkan hal tersebut, Gambar 2 dikategorikan dalam model struktural. Hal ini sesuai dengan ciri model struktural yang dijelaskan oleh Werner et al. (2017), model struktural adalah model yang mampu menggambarkan aspek secara anatomi maupun morfologis. Selain itu hanya difokuskan pada aspek struktur dan struktural dari objek tersebut. Dalam jenis ilmu pengetahuan, Gambar 2 digolongkan dalam jenis pengetahuan konseptual yang mencakup pengetahuan tentang kategori, kelas, bagian, atau susunan, salah satu contohnya mampu membedakan susunan atau struktur dari sel prokariotik dan eukariotik.

Lain halnya dengan subkategori model fungsional dan struktral-fungsional. Dalam LKS MGMP Biologi telah ditemukan sebanyak 36 dan 27 untuk masing-masing subkategori tersebut. Model fungsional mampu menggambarkan suatu proses dan hubungan. Fokusnya 
terhadap proses, fungsi, dan hubungan sebab akibat dari suatu gambar. Sementara itu, model stuktural-fungsional mampu menggambarkan struktur suatu objek, proses, fungsi, dan hubungan sebab akibat atau dalam hal ini dapat dikatakan merupakan gabungan dari model struktural dan fungsional.

Dalam jenis ilmu pengetahuan, hal-hal yang berkaitan dengan proses, fungsi, dan suatu hubungan sebab akibat, digolongkan dalam jenis ilmu pengetahuan prosedural berisi tentang langkah-langkah (proses) atau tahapan yang harus diikuti dalam mengerjakan suatu hal tertentu (Widodo, 2005). Adapun sebagai contoh dari kedua model, disajikan dalam Gambar 3 dan 4 sebagai berikut:

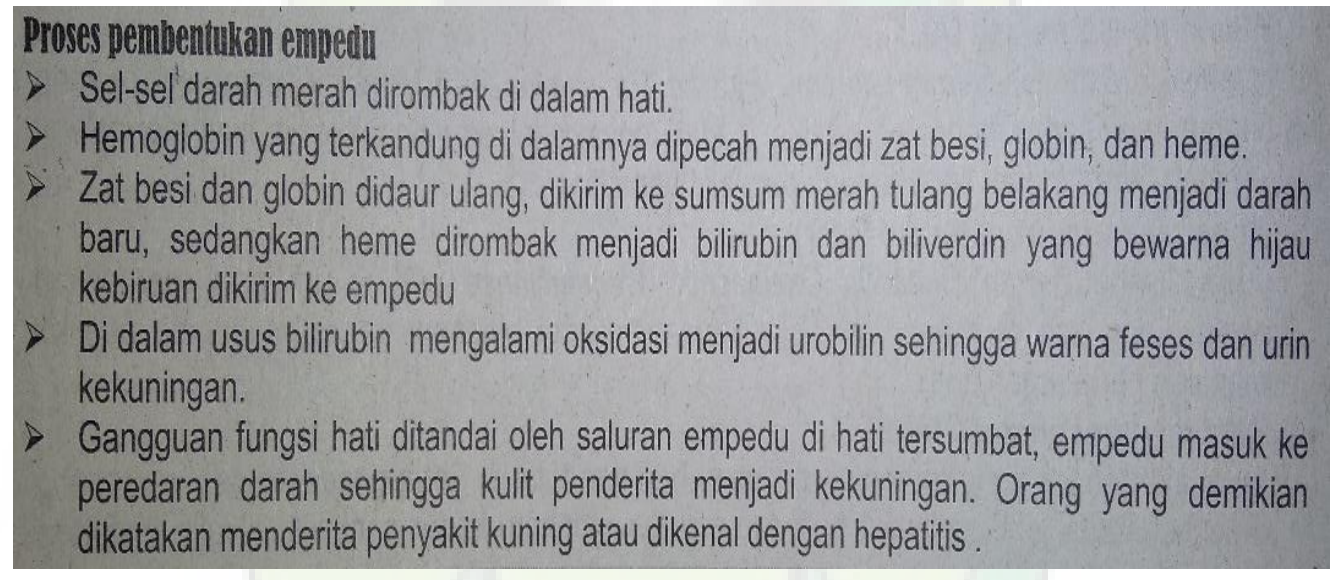

Gambar 3. Contoh Karakteristik Ilustrasi Subkategori Model Fungsional 8H/18

Gambar 3 merupakan contoh dari karakteristik aspek ilustrasi subkategori model fungsional pada kode $8 \mathrm{H} / 18$ yang berarti sebuah contoh dari materi semester 2 , BAB 8 , materi sistem eksresi, terdapat pada halaman 18 LKS. Dari Gambar 3 menjelaskan proses pembentukan empedu. Meskipun tidak digambarkan dengan rinci secara struktural, dari penjelasan tersebut dapat diketahui suatu proses dan hubungan yang terjadi selama proses pembentukan empedu terjadi sejak dirombaknya sel-sel darah merah di dalam hati hingga di dalam usus bilirubin mengalami oksidasi, beserta gangguannya. 


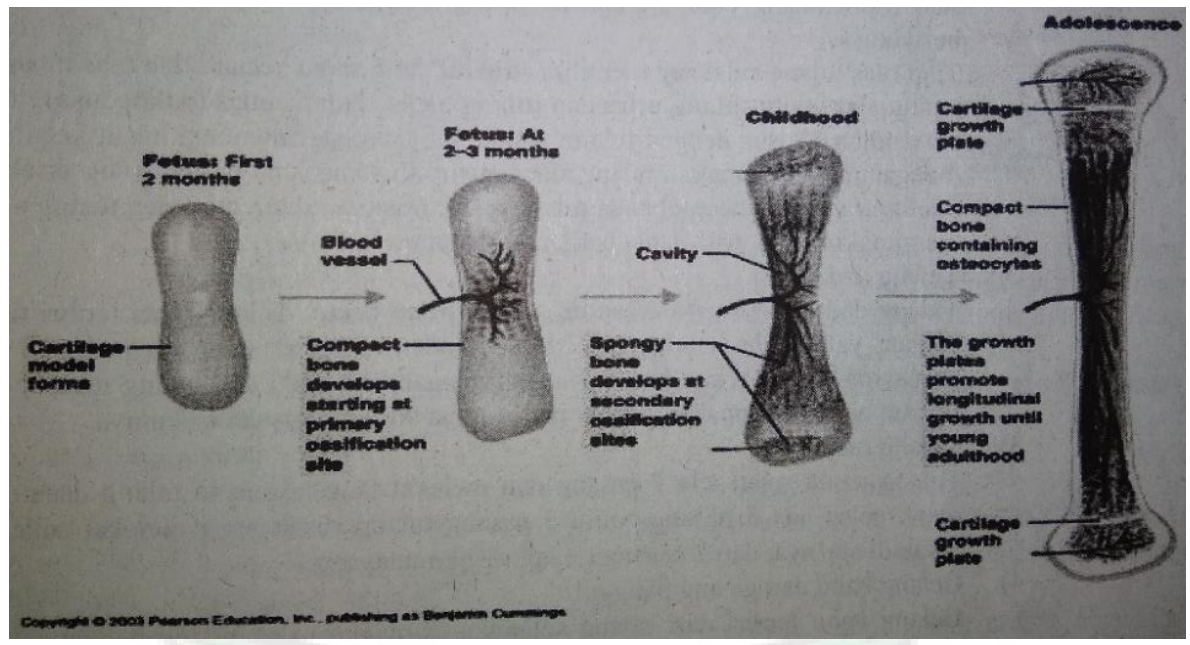

Gambar 4. Contoh Karakteristik Aspek Ilustrasi Subkategori Model Struktural-fungsional $4 \mathrm{D} / 47$

Gambar 4 merupakan contoh dari karakteristik aspek ilustrasi subkategori model struktural-fungsional pada kode 4D/47 yang berarti sebuah contoh dari materi semester 1 , BAB 4, materi sistem gerak, terdapat pada halaman 47 LKS. Dari Gambar 4 dapat diketahui sebuah gambar potongan tulang lengkap dengan strukturnya dan bagaiamana proses perkembangannya secara rinci, serta adanya hubungan sebab akibat mengapa tulang dapat berkembang.

\section{SIMPULAN}

Berdasarkan hasil penelitian mengenai "Pola karakteristik ilustrasi model dalam Lembar Kerja Siswa (LKS) MGMP Biologi Kelas 11 SMA Negeri di Kota Semarang”, maka dapat diambil kesimpulan bahwa karakteristik ilustrasi yang terdiri dari 3 subkategori, subkategori model struktural lebih banyak ditemukan, yaitu sebanyak 67 atau 51,53\% dibandingkan model fungsional yang berjumlah 36 atau 27,69\%, dan model struktural-fungsional yang berjumlah 27 atau 20,76\%. Hasil analisis pola karakteristik ilustrasi model dalam LKS MGMP Biologi Kelas 11 tersebut sesuai dengan ciri-ciri Ilmu Biologi, serta karakteristik jenis pengetahuan yang terdiri dari faktual, konseptual, dan prosedural. Hasil penelitian ini dapat dijadikan bahan evaluasi terhadap LKS yang disusun oleh Tim MGMP Biologi Kota Semarang guna meningkatkan kualitas LKS tersebut sesuai yang telah diharapkan sebelum penelitian, seperti dengan adanya penambahan warna pada gambar-gambar yang dicantumkan, agar lebih memudahkan siswa dalam memahami kedetailan isi atau pesan yang ingin disampaikan gambar. Gambar yang jelas secara warna maupun estetika warna dapat memudahkan siswa memahami pola pemodelannya, serta memudahkan peneliti berikutnya 
dalam analisis berkenaan dengan pemodelan pula. Selain itu, hasil dari penelian pola karakteristik ilustrasi model semoga dapat menjadi acuan bagi pengembangan penelitian berikutnya berkenaan dengan pemodelan.

\section{REFERENSI}

Belzen, U.Z., dan D. Kruger. (2010). Modellkompetenz im Biologieunterricht [Model competence in biology education]. Zeitschrift für Didaktik der Naturwissenschaften.

Gogolin, S dan D. Kruger. 2018. Students' understanding of the nature and purpose of models. Wiley JRST. DOI: 10.1002/tea.21453

Huberman, Miles, dan Saldana. 2014. Analisis Data Kualitatif, Jakarta: Universitas Indonesia.

Karsono. 2017. Pengaruh Penggunaan LKS Berbasis HOTS terhadap Motivasi dan Hasil Belajar IPA Siswa SMP. Jurnal Pendidikan Matematika dan Sains, V (1), 2017, ISSN: $1410-1866$.

Malahayati, E.N. 2017. Pengaruh Lembar Kerja Siswa (LKS) Berbasis Creative Problem Solving (CPS) Pada Materi Keanekaragaman Hayati Untuk Meningkatkan Kemampuan Berpikir Kritis dan Hasil Belajar Siswa Kelas X SMAN 4 Blitar. Jurnal Konstruktivisme, Vol. 9, No. 2, p-ISSN: 1979-9438.

Pluta, W.J., C.A. Chinn, dan R.G. Duncan. 2011. Learners' Epistemic Criteria for Good Scientific Models. Journal Of Research In Science Teaching Vol. 48, No. 5, pp. 486511.

Schwarz, C.V., B.J. Reiser, E.A. Davis, L. Kenyon, A. Acher, .., Y. Yael Shwartz. 2009. Developing a Learning Progression for Scientific Modeling: Making Scientific Modeling Accessible and Meaningful for Learners. Journal of Research in Science Teaching Vol. 46, No. 6, pp. 632-654.

Seok, P., dan S. Jin. 2011. What Teachers of Science Need to Know about Models: An overview. International Journal of Science Education Vol. 33, No. 8, pp. 1109-1130.

Sugiyono. 2018. Metode Penelitian Pendidikan Kuantitatif, Kualitatif, dan R\&D. Bandung: Alfabeta.

Wardani, R. 2018. 21 $1^{\text {st }}$ Century Educator: Menyongsong Transformasi Pendidikan 4.0 : Seminar Nasional Dinamika Informatika SENADI UPY. Yogyakarta.

Werner, S., C. Fortchs, dan W. Boone. 2017. Investigating How German Biology Teachers Use Three-Dimensional Physical Models in Classroom Instruction: a Video Study. Res Sci Educ. DOI 10.1007/s11165-017-9624-4. Springer Science+Business Media Dordrecht.

White, B. Y., A. Collins, dan J.R. Frederiksen. 2011. The nature of scientific metaknowledge. In M. S. Khine \& I. M. Saleh (Eds.), Models and modeling: cognitive tools for scientific enquiry (pp. 3-22). Heidelberg: Springer.

Widodo, A. 2005. Taksonomi Tujuan Pembelajaran. Didaktis: Universitas Pendidikan Indonesia. 